\title{
Application of methylol urea/natural rubber copolymer composite for emulsion paint formulation
}

\author{
S. A. OSEMEAHON ${ }^{1 *}$, I. I. NKAFAMIYA ${ }^{1}$ and F. Y. FAI ${ }^{1}$ \\ ${ }^{1}$ Department of Chemistry, Federal University of Technology, Yola, Nigeria. \\ ${ }^{*}$ Corresponding author, E-mail: sundayosemeahon@yahoo.com
}

\begin{abstract}
This work is a follow up to our quest to develop emulsion paint from amino resin. Both pure urea methylol (MU) and methylol urea/Nature rubber (MU/NR) blend were prepared. Some physico-chemical properties such as viscosity, melting point, moisture uptake, refractive index, density, elongation at break and formaldehyde emission of both MU and MU/NR were evaluated. The result revealed that MU/NR blend possesses better water resistant, hardness, flexibility and low formaldehyde mission while the pure MU gave better refractive index. Emulsion paints were also formulated from both resins and some physico-chemical properties namely $\mathrm{pH}$, viscosity, flexibility, hardness, tackiness, resistance to blistering, dry time, gloss and storage stability were investigated. Emulsion paint derived from MU/NR binder except for gloss passed the entire test conducted while the one from pure MU binder failed flexibility, adhesion, hardness, tackiness and dry time. This work presents MU/NR paint as a high quality one and hence, may introduce a novel emulsion paint derived from MU/NR binder into the coating industry.
\end{abstract}

(C) 2009 International Formulae Group. All rights reserved.

Key words: Amino resin, methylol urea, natural rubber, binder, emulsion paint.

\section{INTRODUCTION}

The coating industry is in innovative mood. The innovation is driven by environment, health, safety, quality improvement and cost reduction. This is especially due to regulations with respect to volatile organic compounds (VOC), which is now challenging companies to find solutions in water-based systems.

With the advent of the regulations on air pollution, and for safety consideration, there have been continued interests in searching for alternative raw materials and new formulations to reduce the overall volatile organic compounds in surface coatings (Gan and Tan, 2001). Recently, much research has focused on replacing solventbased paints with water-based paints (Mohammed et al., 2001; Li and Zeng, 2002). The advantages of water-borne paint include being nonpolluting, easy to handle, quick drying, economic and environmentally friendly. However, although most household paints are water-based, this is not true of industrial paints. Because of the special requirements of the industrial coatings, satisfactory water-based polymers with the required properties have not yet been developed (Gooch, 1997). Therefore a significant challenge in this drive to reduce VOC is the need for the water-borne technology to deliver the enamel type 
properties characteristic of solvent-borne coatings.

The acceptance of urea formaldehyde resin (UF) as a universal material in many engineering areas such as in the coating industry is impeded by some of its inherent qualities such as brittleness, poor water resistance and formaldehyde emission (Barminas and Osemeahon, 2006; Osemeahon and Barminas, 2007). These disadvantages limit its uses. However, UF resins offer a wide range of conditions that make synthesis of these resins with important properties such as gel time, tack and spreading ability of the uncured resin possible. Also, formaldehyde emissions and the durability of the cured resin can be controlled and specifically tailored for the final use of the resins (Osemeahon and Barminas, 2006a, 2006b).

In our earlier experiments (Barminas and Osemeahon, 2007; Osemeahon and Barminas, 2007), we reported both the synthesis of UF through a new synthetic route and the successful copolymerization of the new class of urea formaldehyde with natural rubber resin as a way of developing a paint binder for emulsion paint formulation from amino resin. This work is a follow-up to this experiment (Osemeahon and Barminas, 2007). It involves preliminary evaluation on the application of the MU/NR composite as a binder for emulsion paint formulation.

\section{MATERIALS AND METHODS}

\section{Chemicals}

Urea, formaldehyde, sodium dihydrogen phosphate, sulphuric acid, sodium hydroxide pellets and sucrose were produced by British Drug House (BDH). Natural rubber (NR) (Hevea brasiliensis) was obtained as an exudate from Rubber Research Institute Benin City, Nigeria. All materials were used as received. Sodium benzoate, dispex, carboxylmethyl cellulose (CMC) foamaster, rutile $\left(\mathrm{TiO}_{2}\right)$, China clay and parish white $\mathrm{CaCO}_{3}$ ) were obtained from Aba market, Nigeria. These chemicals were used as purchased.

\section{Resin synthesis}

Trimethylol urea was prepared by reacting one mole $(6.0 \mathrm{~g})$ of urea with three moles $(24.3 \mathrm{ml})$ of $37 \%(\mathrm{w} / \mathrm{v})$ formaldehyde using $0.2 \mathrm{~g}$ of sodium dihydrogen phosphate as catalyst (Osemeahon and Barminas, 2007). The $\mathrm{pH}$ of the solution was adjusted to 6 using $0.5 \mathrm{M} \mathrm{H}_{2} \mathrm{SO}_{4}$ and $1.0 \mathrm{M} \mathrm{NaOH}$ solutions. The solution was then heated in thermostatically controlled water bath at $70{ }^{\circ} \mathrm{C}$. The reaction was allowed to proceed for $2 \mathrm{~h}$ after which the sample was removed and kept at room temperature $\left(30^{\circ} \mathrm{C}\right)$.

\section{Preparation of MU-NR blend and films}

Blend of MU and NR was prepared by adding $50.0 \mathrm{ml}$ of $\mathrm{NR}$ to $50.0 \mathrm{ml}$ of MU to give $50 \%$ of NR in MU. The mixture was stirred with a glass rod and left for $24 \mathrm{~h}$ at room temperature $\left(30{ }^{\circ} \mathrm{C}\right)$. For film preparations, resins from MU and MU/NR were then poured into different glass petri dishes for casting using the solution casting method (Barminas and Osemeahon, 2006). The resins were also allowed to cure and set for seven days at $30{ }^{\circ} \mathrm{C}$. The physical properties of the films were then investigated.

\section{Determination of physical properties \\ Determination of viscosity, density, melting point and refractive index}

The viscosity of the polymer blend and that of the pure MU resins were obtained from a previous method (Barminas and Osemeahon, 2006). In brief, a $100 \mathrm{ml}$ Phywe made graduated glass macro-syringe was utilized for the measurement. The apparatus was standardized with $20 \%$ (W/V) sucrose solution whose viscosity is $2.0 \mathrm{mPa}$.s at $30{ }^{\circ} \mathrm{C}$. The viscosity of the resin was evaluated in relation to that of the standard sucrose solution at $30{ }^{\circ} \mathrm{C}$. Other physical properties were determined according to AOAC Method of Analysis (AOAC, 2000). The densities of the different resins were determined by taking the weight of a known volume of resin inside a density bottle using Metler At400 weighing balance. Five readings were made for each sample and average value calculated. The 
melting point of the different film samples were determined by using Galenkamp melting point apparatus model MFB600-010F. The refractive index of resin samples were determined by using Abbe refractometer. For each test, triplicate determinations were made and mean value recorded.

\section{Determination of moisture uptake}

The moisture uptakes of the different resin films were determined gravimetrically. Known weight of each of the samples were introduced into a desiccator containing a saturated solution of sodium chloride. The wet weights of each sample was then monitored until a maximum weight was obtained. The difference between the wet weight and dry weight of each sample was then recorded as the moisture intake by the resin (Barminas and Osemeahon, 2007). Triplicate determinations were made for each sample and mean value recorded.

\section{Tensile test}

Tensile properties (tensile strength and elongation at break) were measured as described by Osemeahon et al. (2007), using Instron Tensile Testing Machine (Model 1026). Resin films of dimension $50 \mathrm{~mm}$ long, $10 \mathrm{~mm}$ wide and $0.15 \mathrm{~mm}$ thick were brought to rapture at a clamp rate of $20 \mathrm{~mm} / \mathrm{min}$ and a full load of $20 \mathrm{~kg}$. A number of five runs were done for each sample and the average elongation evaluated and expressed as the percentage increase in length.

\section{Determination of formaldehyde emission}

Formaldehyde emission test was performed by using the standard $2 \mathrm{~h}$ desiccator test as earlier reported (Osemeahon and Barminas, 2007). The mold used was made from aluminium foil with a dimension of 69.6 $\mathrm{mm} \times 126.5 \mathrm{~mm}$ and thickness of $12.0 \mathrm{~mm}$. The emitted formaldehyde was absorbed in $25.0 \mathrm{ml}$ water and analyzed by a refractometric technique using Abbe refractometer. Triplicate samples were used and average value taken.

\section{Paint formulation}

The method described by Eze and Uwakwe (2004) was adopted for the paint formulation. A volume of $180 \mathrm{ml}$ of distilled water was introduced into a liter mixing tank and the overhead stirrer switched on. An amount of $0.2 \mathrm{~g}$ of the antifoam was added followed by the addition of the dispersant and the suspenders with the temperature of the mixture maintained at $60{ }^{\circ} \mathrm{C}$ for 5 minutes. Rutile $\left(\mathrm{TiO}_{2}\right)$, China clay and Paris white $\left(\mathrm{CaCO}_{3}\right)$ were then added. This was followed by the addition of thickener, binder (MU) and the stabilizer (Butanol). The mixture was then made up to $500 \mathrm{ml}$ with distilled water. This process was repeated for MU/NR binder. The details of the formulations are shown in Table 1.

\section{Test procedures for paint samples \\ Paint samples were analysed} according to standard organization of Nigeria methods (SON, 1990). Viscosity of paint sample was determined by using an I.C.I. Rotothinner viscometer. The $500 \mathrm{ml}$ tin sample container of the instrument was filled with paint sample under test to $0.3 \mathrm{~mm}$ of the top rim of the dept gauge. The sample was stirred with a thermometer and the temperature maintained at $27{ }^{\circ} \mathrm{C}$. The container with the paint sample was placed in the processing ring on the turntable and the lever pulled down to switch on the motor automatically. The disc was then allowed to run until a steady state was reached (5 minutes). At the end of the required time, the viscosity was recorded in poises. Triplicate determinations were made for each sample and mean value recorded. The $\mathrm{pH}$ of paint sample was determined by using Phywe $\mathrm{pH}$ meter model 18195.04 .

Opacity was determined by using the standard Mohest Chart. The paint sample was applied on Mohest Chart (i.e. hiding power chart) and allowed to dry for $24 \mathrm{~h}$. The opacity was then evaluated by comparing the dried sample film with the hiding power chart. Three determinations were made for each sample and mean value assessment recorded. 
Table 1: Recipe for the formulation of emulsion paints from MU and MU/NR binders.

\begin{tabular}{lcc}
\hline Raw Material & \multicolumn{2}{c}{ Amount used (g) } \\
\hline Sodium benzoate & 0.2 & 0.2 \\
Dispex & 0.4 & 0.4 \\
Carboxyl methyl cellulose (CMC) & 2.5 & 2.5 \\
Foamaster & 0.2 & 0.2 \\
Rutile $\left(\mathrm{TiO}_{2}\right)$ & 54.64 & 54.64 \\
China Clay & 32.21 & 32.21 \\
Parish white $\left(\mathrm{CaCO}_{3}\right)$ & 68.20 & 68.20 \\
Binder (v/v) & & \\
$\quad$ MU & 160 & - \\
$\quad$ MU/NR $(1: 1)$ & - & 85 \\
Butanol & 5 & 5 \\
\hline
\end{tabular}

To evaluate the dry time, paint sample was applied on a glass panel with the aid of bar applicator and allowed to dry. Dry to touch was taken when the paint film was no longer sticking to the finger and dry to hard taken when the film resisted finger print. Triplicate evaluations were made for each sample and mean value assessment recorded. For flexibility test, paint sample was applied on a freshly degreased and chromated aluminum with the aid of paint applicator. The film was then allowed to air dry under room temperature $\left(27^{\circ} \mathrm{C}\right)$ for 7 days. The panel with the film was then inserted into the conical Mandrel Bend Tester and the panel bent through $180^{\circ}$ with a smooth action (taking $1-$ 2 seconds). The panel was then removed from the tester and examined for cracking or loss of adhesion. Any crack or loss of adhesion indicates inflexibility or brittleness. Triplicate samples were made and average evaluation taken.

To evaluate the adhesion property of paints, a coat of paint film was applied with film applicator on a degreased metal panel and allowed to dry for 48 hours. Two sets of lines, one crossing perpendicularly over the other were drawn with a crosshatch tester on the paint film. An adhesive tape was pressed firmly with the thumb covering all the interactions of the perpendicular line. The adhesive tape was held at its loose ends and forcibly removed from the panel. Removal of more than $50 \%$ of the square lines of the paint film indicates poor adhesion. Triplicate determinations were made at $27{ }^{\circ} \mathrm{C}$ for each sample and average assessment recorded. Specular gloss at $85^{\circ}$ of paint sample was determined by using gloss meter (Digital instruments, model RSPT-20). Paint film was prepared by using 4mesh (100 microns) applicator over a precleaned glass panel and the film allowed to dry for $24 \mathrm{~h}$. The ASTM gloss-meter was allowed to warmed up for 10 min and using the black glass standard held against the pot-hole, the meter was adjusted to read $92.5 \%$. The sample cast on the glass panel was then held against the pot-hole in three separate positions along its length and the mean gloss calculated in \% with a difference of not more than $5 \%$ between the highest and the lowest. Triplicate measurements were made for each sample and mean value recorded.

This was done qualitatively on the dried film by hand feeling to find out if the paint film is sticky or not. Stickiness of a dried paint film is an indication that the film is tacky. Triplicate samples were used for each determination and the average quality assessment recorded. To test for resistance to blistering, undiluted paint sample was applied to a glass panel with an applicator to give a wet film thickness of about $120 \mu \mathrm{m}$ and was allowed to dry for $24 \mathrm{~h}$. At the end of this period $4 \mathrm{ml}$ of distilled water in the form of 
circular drop was placed on the film. The presence of blistering, wrinkling, swelling or cracking within a period of 30 minutes indicates poor water resistance. Triplicate samples were used for each determination and the average quality assessment recorded. For the stability test, the paint sample was fully sealed in a container and allowed to stay at room temperature $\left(27{ }^{\circ} \mathrm{C}\right)$ for 12 months. At the end of this incubation period, the sample was re-examined for any change in viscosity or coagulation of the emulsion paint. Absence of coagulation or any change in viscosity is regarded as a pass. Triplicate samples were used for each determination and the average value recorded.

To evaluate the chemical resistant of the paint films, three flexible aluminum panels $(150 \mathrm{~mm} \times 150 \mathrm{~mm} \times 0.3 \mathrm{~mm})$ were used as the test panels. A coat of paint with paint applicator was applied to the panel. One liter glass beaker was filled with $0.1 \mathrm{M} \mathrm{NaOH}$ solution to a depth of $150 \mathrm{~mm}$ and the test piece immersed for $48 \mathrm{~h}$ to the depth of approximately $120 \mathrm{~mm}$. The test piece was removed, washed with running water and stood to dry for $2 \mathrm{~h}$. The above procedure was repeated by using $0.1 \mathrm{M} \mathrm{HCl}$ and $0.1 \mathrm{M} \mathrm{NaCl}$ respectively. The presence of any surface defects such as cracking, blistering, peeling or change in color indicates poor chemical resistance. Pencil hardness of the paint films was also determined according to ASTM standard method (ASTM D 3363-74).

\section{RESULTS}

Table 2 compares some physical properties of pure methylol urea (MU) and MU/NR copolymer composite. It was observed that the viscosity, melting point and elongated at break of MU/NR blend are very high compared to those of MU. The increase in viscosity is due to increase in molecular weight, which is a consequence of the reactive, blending between $\mathrm{MU}$ and NR (Osemeahon and Barminas, 2007). The relatively high melting point of MU/NR is due to the high molecular weight and cross density of MU/NR composite as reflected in the high viscosity value. The density, moisture uptake, refractive index and formaldehyde emission of MU/NR are relatively very low compared to those of MU. The decrease in density with NR presence in MU/NR blend can be ascribed to inefficient molecular chain packing as density depends on free volume and packing efficiency of molecular chain (Chain and Yi, 2001).

The low moisture uptake and formaldehyde emission recorded in MU/NR blend is explained by the reduction in MU loading in the presence of the hydrophobic NR resin. Cured NR is resistant to moisture uptake (Osemeahon and Berminas, 2007). The relative low refractive index of MU/NR blend agrees with literature reports (Gupta et al., 2001; Osemeahon and Barminas, 2007). This is due to micro phase separation between $\mathrm{MU}$ and NR.

\section{Some physical properties of paints formulated from MU and MU/NR binders}

Some physical properties of MU and MU/NR paints are tabulated in Table 3. In this table, some properties such as $\mathrm{pH}$, viscosity, flexibility and opacity of both MU and MU/NR paint falls within acceptable ranges for paints (SON, 1990). MU/NR paint displayed good adhesion, tackiness and hardness properties, but the pure MU paint presented poor adhesion, hardness and tack properties. The behavior of the MU paint can be attributed to low molecular weight and hence low crosslink density of the pure MU binder (Osemeahon and Barminas, 2007).

The results of resistance to blistering (water resistance) of the different paint formulations are also provided in Table 3. The paint from the MU/NR binder passed resistance to blistering test while those formulated with the pure MU binder failed the test. The above results indicate that NR segment has been cross linked into the MU/NR copolymer thus making the resulting binder water resistant. Also, the presence of cured NR in MU/NR binder, presents hydrophobic segment, which helped to increase the water resistance of the resulting 
Table 2: Some physicochemical properties of the synthesized MU and MU/NR binders.

\begin{tabular}{lcc}
\hline Property & MU & MU/NR \\
\hline Viscosity $(\mathrm{mPa} . \mathrm{s})$ & $3.41 \pm 0.04$ & $248.03 \pm 2.51$ \\
Melting point $\left({ }^{\circ} \mathrm{C}\right)$ & $214.00 \pm 2.41$ & $255.00 \pm 2.57$ \\
Density $\left(\mathrm{g} / \mathrm{cm}^{3}\right)$ & $1.102 \pm 0.020$ & $0.641 \pm 0.010$ \\
Moisture Uptake $(\%)$ & $3.261 \pm 0.021$ & $1.341 \pm 0.020$ \\
Refractive index & $1.4104 \pm 0.0061$ & $1.3411 \pm 0.0057$ \\
Formaldehyde emission $(\mathrm{ppm})$ & $0.948 \pm 0.001$ & $0.058 \pm 0.000$ \\
Elongation at break $\left(\mathrm{kg} / \mathrm{cm}^{2}\right)$ & $115.03 \pm 1.02$ & $350.43 \pm 2.18$ \\
\hline
\end{tabular}

Figure 3: Some Physical Properties of Paints Formulated From MU and Modified MU Binders.

\begin{tabular}{lccc}
\hline Parameter & MU & MU/NR & SON Standard \\
\hline pH & 7.1 & 7.6 & $7-8.5$ \\
Viscosity (poise) & 6.5 & 11.5 & $6-15$ \\
Flexibility & $\mathrm{P}$ & $\mathrm{P}$ & $\mathrm{P}$ \\
Opacity & $\mathrm{P}$ & $\mathrm{P}$ & $\mathrm{P}$ \\
Adhesion & $\mathrm{F}$ & $\mathrm{P}$ & $\mathrm{P}$ \\
Hardness & $\mathrm{F}$ & $\mathrm{P}$ & $\mathrm{P}$ \\
Tackiness & $\mathrm{F}$ & $\mathrm{P}$ & $\mathrm{P}$ \\
Resistance to blistering & $\mathrm{F}$ & $\mathrm{P}$ & $\mathrm{P}$ \\
Drying time (min) & & & \\
$\quad$ Touch & 180 & 18 & 20 \\
$\quad$ Hard & 720 & 110 & 120 \\
Storage Stability (12 months) & $\mathrm{P}$ & $\mathrm{P}$ & $\mathrm{P}$ \\
85 ${ }^{0}$ Gloss & 28.4 & 15.2 & $16-50$ \\
Pencil hardness & $2 \mathrm{~B}$ & $\mathrm{H}$ & - \\
\hline P and F means pass and fail SON test, respectively & & &
\end{tabular}

paint formulation ( $\mathrm{Wu}$ et al., 2001). The inability of the pure MU paint to pass the resistance to blistering test can be attributed to the inherent property of urea formaldehyde resin couple with the low molecular weight of the MU binder employed in the paint formulation (Conner, 1996; Nogueria et al., 2001).

The drying times of MU/NR paint presented in Table 3 is within acceptable standard range while that of MU paint is outside the range (SON, 1990). The long period of drying exhibited by MU paint is attributable to the low molecular weight and hence low crosslink density of the MU binder (Lowel, 1990). The gloss of MU is within acceptable standard range. The low gloss of MU/NR is expected and it is due to low refractive index of the MU/NR binder. Stability in storage is an important consideration for coating systems (Lowel, 1990). In the usage of amino resin as a paint binder the resin can undergo self-condensation and if this happens, the system may become too viscous and gel-like for use in the coating application intended. This, therefore, calls for the addition of a stabilizer (Butanol) into the formulation. From Table 3, all the formulations passed the standard stability test meaning that this problem has been successfully controlled. 
Table 4: Chemical resistance of paint films.

\begin{tabular}{lccc}
\hline & & Media & \\
\hline Samples & $0.1 \mathrm{M} \mathrm{NaCl}$ & $0.1 \mathrm{M} \mathrm{HCl}$ & $0.1 \mathrm{M} \mathrm{NaOH}$ \\
MU & $\mathrm{a}$ & $\mathrm{b}$ & $\mathrm{c}$ \\
$\mathrm{MU} / \mathrm{NR}$ & $\mathrm{a}$ & $\mathrm{a}$ & $\mathrm{a}$ \\
\hline $\mathrm{a}=$ No effect, & $\mathrm{b}=$ cracking, & $\mathrm{c}=$ blistering
\end{tabular}

\section{Chemical resistance of paint films}

The chemical resistance of the paint films to different solvent media are shown in Table 4. From the results, both MU and MU/NR are unaffected by the salt medium. MU/NR films are also not affected by both the acid and alkali solutions. However, surface defects were observed in the case of MU films both in alkali and acid solutions. These results indicate that MU/NR paint has better chemical resistance than MU paint. These differences are attributable to the differences in the different binders to resist $\mathrm{pH}$ changes in the various media (Barminas and Osemeahon, 2007).

\section{Conclusion}

We prepared raw methylol urea and methylol Urea/Natural rubber blend. Some physical properties of both MU and MU/NR were studied. The result revealed that MU/NR blend possesses better water resistant, hardness, flexibility and lower formaldehyde emission while the pure MU gave better refractive index. Both $\mathrm{MU}$ and MU/NR binders were also used to formulate emulsion paints. Emulsion paints from MU/NR gave better quality paint in terms of the physical and chemical tests conducted. This work may, therefore, introduce a novel emulsion paint derived from MU/NR binder into the coating industry.

\section{REFERENCES}

AOAC 2000. Official Method of Analysis International $\left(17^{\text {th }}\right.$ edn) Horwitz W (ed). Gaithersburg Mongland: USA; 1-68.
ASTM D 3363-74. 1979. Test for Film Hardness by Pencil Test. Annual Book of American Society for Testing, and Material Standards, Philadephia, PA. 29: 712-717.

Barminas JT, Osemeahon SA. 2006. Development of amino resins for paint formulation. 11. Effect of temperature on new synthetic route. European Journal of Scientific Research, 14: 489-499.

Barminas JT, Osemeahon SA. 2007. Development of amino resins for paint formulation. 1. Effect of $\mathrm{pH}$ on a new synthetic route. European Journal of Scientific Research, 16: 160-173.

Chain KS, Yi S. 2001. Synthesis and characterization of an isocyanurate oxazolidone polymer: Effect of stoichiometry. J. Appl. Poly. Sci., 82: 879-888.

Conner HA. 1996. Urea - formaldehyde adhesive resins. In Encyclopedia of Polymeric Material (vol. 2), Salamone JC (ed). pp. 8495-8500.

Eze SO, Uwakwe CO. 2004. Effect of different commercial brands of paint thickner on the performance of latex emulsion paints. Proceedings of the $27^{\text {th }}$ International Conference of the Chemical Society of Nigeria, pp 390 - 391 .

Gan S, Tan B. 2001. FTIR studies of the curing reactions of palm oil alkydmelamine enamels. J. Appl. Polym. Sci., 80: $2309-2315$.

Gooch JW. 1997. Analytical and Reformulation of Polymeric Materials: Paints, Plastics, Adhesives and Inks. 
Kluwer Academic Publichers: New York, USA; 119-120.

Gupta S, Mendon KS, Thames FS. 2001. Application of epoxidized and hydroxyfluoroester pendent secondary highmolecular-weight guayule rubber in coating. J. Appl. Polym. Sci., 82: $1718-$ 1724.

Li S, Zeng W. 2002. Effect of crosslinker, buffer, and blending on damping properties of poly (styrene acrylonitrile)/poly (ethyl acrylate - n butyl acrylate) latex inter penetrating polymer networks. J. Appl. Polym. Sci., 84: 2347 - 2351 .

Lowel HJ. 1990. Coatings. In Encyclopedia of Polymer Science and Engineering, Kroschwitz JI, Mark HF, Bikales NM, Overberger CG, Menges G (eds). Vol. 3, p. 615.

Mohammed AH, Bardam MB, Aglan AH. 2001. Waterborne methylamine adduct as corrosion inhibitor for surface coating. $J$. Appl. Polym. Sci., 80: 286 - 296.

Nogueira PC, Ramirez A, Torres MI, Abad J, Cano I, Lopez-bueno I, Barral L. 2001. Effect of water sorption on the structure and mechanical properties of an epoxy resin system. J. Appl. Polym. Sci., 80: 7180 .
Osemeahon SA, Barminas JT. 2006a. Properties of a low viscosity urea formaldehyde resin prepared through a new synthetic route. Bull. Pure Appl. Sci., 25C: 67-76.

Osemeahon SA, Barminas JT. 2006b. a new synthetic route for amino resin for paint formulation: effect of sodium dihydrogen phosphate $\left(\mathrm{NaH}_{2} \mathrm{PO}_{4}\right)$ as catalyst. Bull. Pure Appl. Sci., 25C: 111-118.

Osemeahon SA, Barminas JT. 2007. Study of a composite from reactive blending of methylol urea resin with natural rubber. Afri. J. Biotechnol., 6(6): 810-817.

Osemeahon SA, Barminas JT, Aliyu BA. 2007. Effect of urea formaldehyde viscosity on some physical properties of a composite from reactive blending of urea formaldehyde with natural rubber. Int. J. Phys. Sci., 2(9): 242-248.

SON. 1990. Standard for Paints and Varnishes Part 6: Test Methods for Paints for Decorative Purposes, pp 1-24.

Wu Q, Xu J, Yu Y. 2001. Novel dibutyltin oxide - tributyl phosphate condensate as accelerator for the curing of the epoxy resin/4', 4'-diamirio diphenyl sulfone system. II. Toughening of the resin with hydroxyl-terminated poly(tetramethylene) glycols. J. Appl. Polym. Sci., 80: 12371242. 